\title{
Radiofrequency ablation induces dedifferentiation of hepatocellular carcinoma
}

\author{
HIDEHIRO TAJIMA ${ }^{1}$, TETSUO OHTA ${ }^{1}$, KOICHI OKAMOTO ${ }^{1}$, SHINICHI NAKANUMA ${ }^{1}$, \\ HIRONORI HAYASHI $^{1}$, HISATOSHI NAKAGAWARA ${ }^{1}$, ICHIRO ONISHI ${ }^{1}$, HIROYUKI TAKAMURA ${ }^{1}$, \\ HIROHISA KITAGAWA ${ }^{1}$, SACHIO FUSHIDA ${ }^{1}$, TAKASHI TANI ${ }^{1}$, TAKASHI FUJIMURA ${ }^{1}$, \\ MASATO KAYAHARA ${ }^{1}$, KUNIAKI ARAI ${ }^{2}$, TATSUYA YAMASHITA ${ }^{2}$, SHUICHI KANEKO ${ }^{2}$ and YOH ZEN ${ }^{3}$ \\ Departments of ${ }^{1}$ Gastroenterological Surgery, ${ }^{2}$ Gastroenterology, Division of Cancer Medicine, \\ Graduate School of Medicine Science, Kanazawa University, ${ }^{3}$ Division of Pathology, \\ Kanazawa University Hospital, 13-1 Takaramachi, Kanazawa 920-8641, Japan
}

Received February 6, 2009; Accepted April 13, 2009

DOI: 10.3892/ol_00000016

\begin{abstract}
Radiofrequency ablation (RFA) has been reported to be a minimally invasive and effective procedure for the treatment of hepatocellular carcinoma (HCC). However, the pattern of recurrence and complications following RFA have yet to be fully identified. During the period January 2000 to December 2006, we performed HCC resections in 15 patients who developed local recurrence after RFA, as well as in 144 patients without RFA. In patients with local recurrence of HCC after RFA, the tumors showed a more invasive growth, more vascular invasion and less differentiation compared with tumors of patients without RFA. In 6 of the 15 patients with recurrence after RFA, needle biopsy of the HCC was performed before tumor ablation. In five of these 6 patients, dedifferentiation of the tumor was observed. These findings suggest that heat shock due to RFA induces dedifferentiation of HCC. Recurrence after RFA may result in an aggressive tumor that precludes any possibility of cure. RFA must not be considered a suitable alternative to surgery in patients with a low surgical risk. Instead, RFA should be performed according to strict indications by skilled operators using the latest devices.
\end{abstract}

\section{Introduction}

Radiofrequency ablation (RFA) has become a favourable technique for the treatment of small hepatocellular carcinoma

Correspondence to: Dr Hidehiro Tajima, Department of Gastroenterological Surgery, Division of Cancer Medicine, Graduate School of Medicine Science, Kanazawa University, 13-1 Takaramachi, Kanazawa 920-8641, Japan

E-mail: hidetajima@surg2.m.kanazawa-u.ac.jp

Key words: hepatocellular carcinoma, dedifferentiation, local recurrence, radiofrequency ablation
(HCC) because of its feasibility, effectiveness, repeatability and safety (1-6). Local therapy for HCC is widely employed, including percutaneous ethanol injection and RFA. A prospective study demonstrated that RFA requires fewer sessions than percutaneous ethanol injection in patients with small HCCs (1). In most $\mathrm{HCC}$ patients, treatment options are limited by patient liver dysfunction caused by underlying chronic inflammation and cirrhosis. Although complete surgical resection of HCC offers the best chance of long-term survival, cirrhosis may limit the extent of parenchymal resection that can be tolerated, increasing the risk of postoperative liver failure and death (7). There is no significant difference of overall or diseasefree survival between surgical resection and RFA when HCC patients are in Child-Pugh class B (8). However, some cases of rapid and aggressive recurrence of HCC after RFA were reported (9-11). In this study, we reviewed 15 resected HCC patients who developed local recurrence after RFA therapy, and we compared their pathological and clinical features with those of resected HCC patients without RFA.

\section{Materials and methods}

Patients. Between January 2000 and December 2006, 174 HCC patients underwent surgery at the Department of Gastroenterological Surgery of Kanazawa University Hospital (Kanazawa, Japan). Among them, 15 patients had developed local recurrence of HCC after RFA therapy. They included 12 men and 3 women with an average age of 62.5 years (range 44-79). In 6 patients, needle biopsy of the HCC was performed before RFA at the Department of Internal Medicine (I) of Kanazawa University Hospital.

Pathological specimens. For this study, formalin-fixed and paraffin-embedded specimens were retrieved from the surgical pathology files of the Pathology Department of Kanazawa University Hospital. The tumors were evaluated according to the general rules for the clinical and pathological study of liver cancer proposed by the Japanese Liver Cancer Group. 
Table I. Baseline data of the two groups.

\begin{tabular}{lccc}
\hline & $\begin{array}{c}\text { Local recurrence } \\
\text { after RFA therapy }\end{array}$ & $\begin{array}{c}\text { Without } \\
\text { RFA }\end{array}$ & p-value \\
\hline Age & 60.5 & 63.5 & N.S. \\
Gender (male:female) & $11: 04$ & $117: 33$ & N.S. \\
Hepatitis B virus & $7(46.7 \%)$ & $52(33.8 \%)$ & N.S. \\
Hepatitis C virus & $7(46.7 \%)$ & $76(49.4 \%)$ & N.S. \\
Non-B non-C & $1(6.6 \%)$ & $26(16.8 \%)$ & N.S. \\
\hline
\end{tabular}

N.S., not significant.

Table II. Pattern of tumor growth.

\begin{tabular}{lcr}
\hline Pattern & $\begin{array}{c}\text { Local recurrence } \\
\text { after RFA }\end{array}$ & $\begin{array}{c}\text { Without } \\
\text { RFA }\end{array}$ \\
\hline $\begin{array}{l}\text { Expansive } \\
\text { Invasive }\end{array}$ & $10(66.7 \%)$ & $138(94.5 \%)$ \\
$\mathrm{p}<0.01$. & $5(33.3 \%)$ & $8 \quad(5.5 \%)$ \\
\hline
\end{tabular}

A

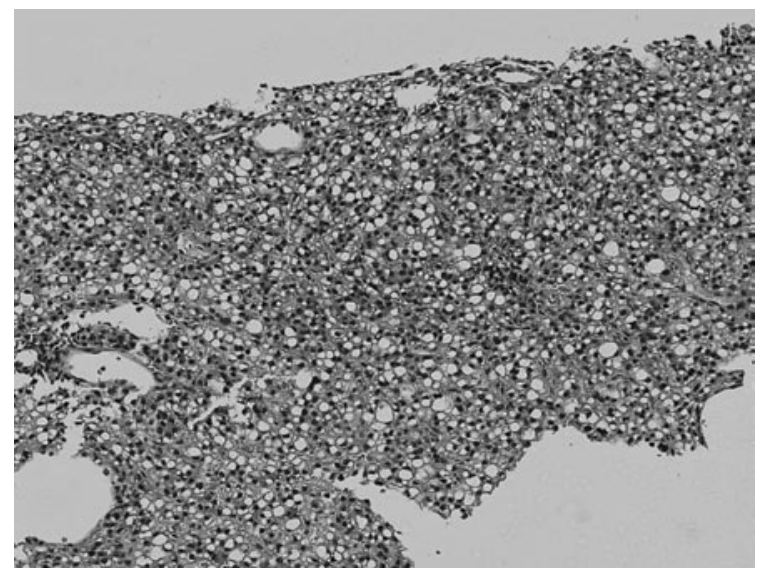

C

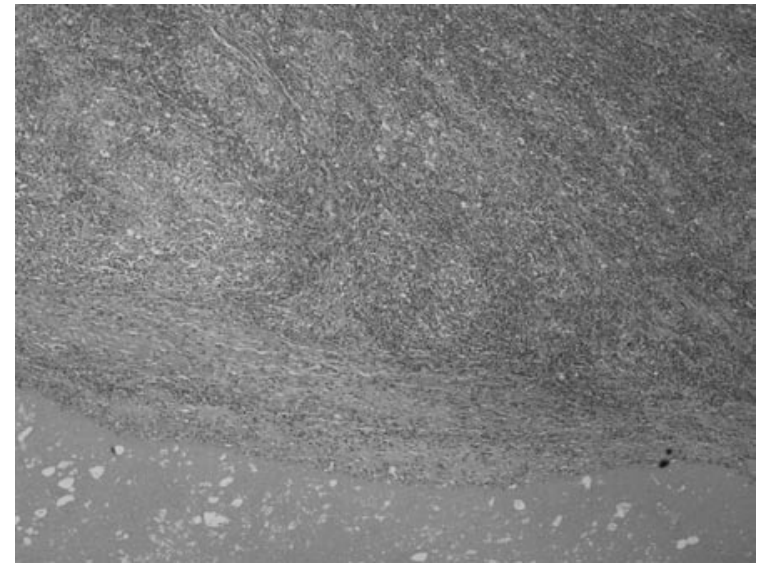

Table III. Differentiation of the resected tumor.

\begin{tabular}{lcc}
\hline Differentiation of HCC & $\begin{array}{c}\text { Local recurrence } \\
\text { after RFA (\%) }\end{array}$ & $\begin{array}{c}\text { Without } \\
\text { RFA (\%) }\end{array}$ \\
\hline Well diff. & $0(0.0)$ & $19(13.2)$ \\
Well-to-moderately diff. & $2(13.3)$ & $19(13.2)$ \\
Moderately diff. & $8(53.3)$ & $85(59.0)$ \\
Moderate to poorly diff. & $1(6.7)$ & $10(6.9)$ \\
Poorly diff. & $4(26.7)$ & $11(7.6)$ \\
\hline
\end{tabular}

$\mathrm{p}<0.05$. Diff., differentiated.

Table IV. Vascular invasion.

\begin{tabular}{lcc}
\hline Vascular invasion & $\begin{array}{c}\text { Local recurrence } \\
\text { after RFA (\%) }\end{array}$ & $\begin{array}{r}\text { Without } \\
\text { RFA (\%) }\end{array}$ \\
\hline Positive & $12(80.0)$ & $56(39.2)$ \\
Negative & $3(20.0)$ & $87(60.8)$ \\
\hline $\mathrm{p}<0.05$. & & \\
\hline
\end{tabular}

B

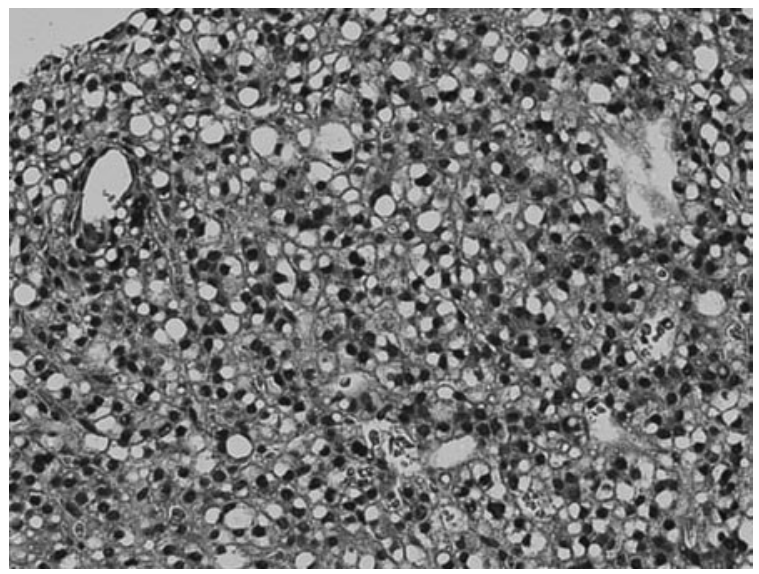

D

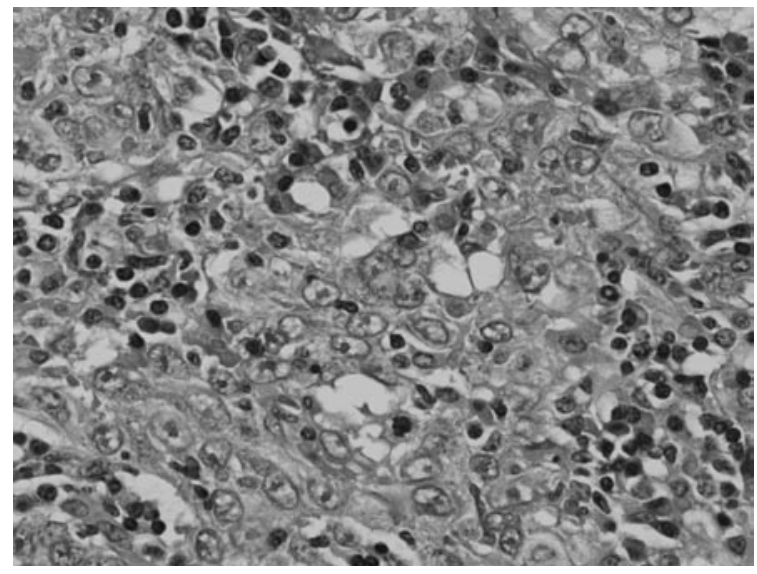

Figure 1. Comparison of pathological findings between a resected local recurrence after RFA and the needle biopsy specimen obtained before RFA (case 1). (A,B) Needle biopsy specimen of HCC obtained before RFA is well differentiated. (C,D) Resected specimen of the recurrent tumor. Besides necrosis due to RFA, a massive growth of poorly differentiated tumor cells is observed. 
Table V. Tumor differentiation before and after RFA.

\begin{tabular}{|c|c|c|}
\hline $\begin{array}{l}\text { Case } \\
\text { number }\end{array}$ & $\begin{array}{l}\text { Differentiation } \\
\text { before RFA } \\
\text { (tumor biopsy) }\end{array}$ & $\begin{array}{l}\text { Differentiation } \\
\text { of the recurrent tumor } \\
\text { (resected specimen) }\end{array}$ \\
\hline 1 & Well diff. & Poorly diff. \\
\hline 2 & Well diff. & Moderately diff. \\
\hline 3 & Well diff. & Moderately diff. \\
\hline 4 & Well diff. & Moderately diff. \\
\hline 5 & Well-to-moderately diff. & Moderately diff. \\
\hline 6 & Moderately diff. & Moderately diff. \\
\hline
\end{tabular}

Diff., differentiated.

Statistical analysis. For statistical analysis, p-values were calculated by a two-tailed test and $\mathrm{p}<0.05$ was considered to indicate statistical significance.

\section{Results}

Four of the 15 HCC patients with local recurrence after RFA therapy had a fatal outcome. One patient presenting with cirrhosis due to hepatitis $\mathrm{C}$, succumbed to hepatic failure caused by fibrosing cholestatic hepatitis after living-related donor liver transplantation, and one patient succumbed to liver failure postoperatively. The other two patients succumbed to tumor recurrence.

There were no significant differences of baseline characteristics, including gender, age and type of hepatitis virus, in patients who developed local recurrence of HCC after RFA and HCC patients without RFA (Table I).

In the 15 patients with local recurrence after RFA, the tumors showed significantly more invasive growth, more vascular invasion and less differentiation compared with those of the 144 patients without RFA (Tables II-IV).

Six patients who developed local recurrence underwent tumor biopsy before starting RFA. In 5 of these 6 patients, dedifferentiation of HCC was observed. One well-differentiated HCC changed to poorly differentiated HCC (Fig. 1), three well-differentiated HCCs changed to moderately differentiated and one well-to-moderately differentiated HCC changed to moderately differentiated. Only one moderately differentiated HCC was unchanged after RFA therapy (Table V).

\section{Discussion}

RFA is now accepted as a curative procedure for liver tumors. The intratumoral application of RF energy for 15-30 min causes coagulative necrosis in a 2.5 - to 5 -cm sphere (12). In order to achieve a good oncological result, this sphere has to include a margin of cancer-free liver tissue that extends at least $1 \mathrm{~cm}$ beyond the tumor. RFA is now used widely and some studies about risk factors for local recurrence of HCC after RFA have been reported (13-14). Hori et al suggested that the most important variables influencing the local recurrence rate were tumor size and location relative to the liver surface (13). It was reported that the laparoscopic approach combined with the artificial pleural effusion and ascites method of percutaneous treatment was effective for the treatment of HCC located just beneath the diaphragm and close to the liver surface (15-17).

The necrotic zone is not spherical when a tumor is located near vessels that can be detected by abdominal computed tomography, magnetic resonance imaging or ultrasonography (18). This is because larger vessels influence the extent of coagulative necrosis produced by RFA via the well-known cooling effect. The final size of the coagulated zone depends on heat loss due to convection through blood flow. This reduction of the necrotic zone by the cooling effect raises the possibility that the local recurrence rate would be higher for tumors situated near vessels. Yamasaki et al reported on the efficacy of RFA with balloon occlusion of the hepatic artery for the treatment of tumors $>30 \mathrm{~mm}$ in diameter (19). However, in the present study, tumor location in relation to blood vessels had no significant influence on the local recurrence rate and tumor vascularity showed no significant relationship to local recurrence after a single session of RFA. These results suggest that arterial blood flow is not likely to decrease the volume of the necrotic zone when a tumor is $<3.0 \mathrm{~cm}$ in diameter.

However, some cases of rapid and aggressive recurrence of HCC after RFA, whose tumors were found to be $<3.0 \mathrm{~cm}$ in diameter, were reported (9-11). Nicoli et al suggested that the RFA needle was able to connect between two vascular territories (the arteries and the portal veins) (4). A possible explanation for the rapid spread of neoplastic cells is that seeding along this new link facilitates the migration of tumor cells from the high-pressure arterial territory to the lowpressure portal territory. It is well known that once HCC cells reach the portal branches, invasion of other liver segments occurs. Thus, in addition to the risk of seeding along the needle track, the risk of intrahepatic spread after insertion of the RFA needle must be considered. The risk of seeding may be high if an arteriovenous fistula is created by the RFA needle. Portolani et al suggested that the thermal energy emitted by the RFA instrument can induce local hypertension and rupture the pseudocapsule, leading to the spread of viable neoplastic cells in the perilesional liver parenchyma or directly into blood vessels or the biliary tract (10). Thus, it is possible that a vascular link between the hepatic arteries and portal veins or an increase of intratumoral pressure resulting from the high temperature during the ablation process releases tumor cells, or that the penetration of the RFA needle into a small portal branch leads to intraportal tumor spread.

In addition, heat stress induces the tyrosine phosphorylation and activation of a human carcinoma dedifferentiation modulator (20). Accordingly, it is suspected that the thermal effect of RFA may increase the malignant potential of the residual viable tumor cells, resulting in rapid and aggressive progression.

Vivarelli et al compared overall and disease-free survival in surgical resection and RFA patients. They reported that resection was superior to RFA in terms of overall and diseasefree survival. However, they also reported that there were no significant differences of overall and disease-free survival between surgical resection and RFA when the patients were in Child-Pugh class B (8). The incidence of local failure after 
RFA was reported to be as low as $1.8 \%$, but reached $12-18 \%$ as reported by other authors (21-23). In our department, the local recurrence rate after RFA is higher compared with that for surgery, but the difference is not significant (8.3 vs. $1.3 \%$, $\mathrm{p}=0.13$ ).

The impact of the complications reported here may temper the optimistic outcome reported in some initial series (21), suggesting that caution is needed with regard to the indications and application of RFA, particularly in patients who are also suitable for surgery. In such patients, the advantage of low mortality and morbidity may be reduced by the possibility of non-curative treatment leading to tumor progression. The risk of aggressive recurrence after RFA must be considered when assessing the options for treatment of HCC. Recurrence after RFA may lead to aggressive tumor evolution that precludes any possibility of cure. RFA should only be considered a suitable alternative to surgery in high-risk patients.

\section{References}

1. Rossi S, Garbagnati F, Lencioni R, et al: Percutaneous radiofrequency thermal ablation of nonresectable hepatocellular carcinoma after occlusion of tumor blood supply. Radiology 217 : 119-126, 2000.

2. Livraghi T, Goldberg SN, Lazzaroni S, et al: Small hepatocellular carcinoma: treatment with radio-frequency ablation versus ethanol injection. Radiology 210: 655-661, 1999.

3. Allgaier HP, Deibert P, Zuber I, et al: Percutaneous radiofrequency interstitial thermal ablation of small hepatocellular carcinoma. Lancet 353: 1676-1677, 1999.

4. Nicoli N, Casaril A, Marchiori L, et al: Intraoperative and percutaneous radiofrequency thermal ablation in the treatment of hepatocellular carcinoma. Chir Ital 52: 29-40, 2000.

5. Nicoli N, Casaril A, Marchiori L, et al: Treatment of recurrent hepatocellular carcinoma by radiofrequency thermal ablation. J Hepatobiliary Pancreat Surg 8: 417-421, 2001.

6. Solbiati L, Livraghi T, Goldberg SN, et al: Percutaneous radiofrequency ablation of hepatic metastases from colorectal cancer: long-term result in 117 patients. Radiology 221: 159-166, 2001.

7. Steven AC, Francesco I, Lee ME, Vauthey JN and Paolo V: Radiofrequency ablation of hepatocellular cancer in 110 patients with cirrhosis. Ann Surg 232: 381-391, 2000.

8. Vivarelli M, Guglielmi A, Ruzzenente A, et al: Surgical resection versus percutaneous radiofrequency ablation in the treatment of hepatocellular carcinoma on cirrhotic liver. Ann Surg 204: 102-107, 2004.

9. Nicoli N, Casaril A, Hilal MA, et al: A case of rapid intrahepatic dissemination of hepatocellular carcinoma after radiofrequency thermal ablation. Am J Surg 188: 165-167, 2004.
10. Portolani N, Tiberio GA, Ronconi M, et al: Aggressive recurrence after radiofrequency ablation of liver neoplasms. Hepatogastroenterology 50: 2179-2184, 2003.

11. Takada Y, Kurata M and Ohkohchi N: Rapid and aggressive recurrence accompanied by portal tumor thrombus after radiofrequency ablation for hepatocellular carcinoma. Int Clin Oncol 8: 332-335, 2003.

12. Wood TF and Bilchik AJ: Radiofrequency thermal ablation as treatment for liver cancer at the John Wayne Cancer Institute. Onc Issue 16: 17-20, 2001.

13. Hori T, Nagata K, Hasuike S, et al: Risk factor for the local recurrence of hepatocellular carcinoma after a single session of percutaneous radiofrequency ablation. J Gastroenterol 38: 977-981, 2003.

14. Ono K, Kokubu S, Hidaka H, et al: Risk factors of delay in restoration of hepatic reserve capacity and local recurrence after radiofrequency ablation therapy for hepatocellular carcinoma (HCC). Hepatology Res 31: 172-177, 2005.

15. Abe T, Shinzawa H, Wakabayashi H, Aoki M, et al: Value of laparoscopic microwave coagulation therapy for hepatocellular carcinoma in relation to tumor size and location. Endoscopy 32: 598-603, 2000.

16. Horigome H, Nomura T, Saso K, Joh T, Ohara H and Itoh M: Artificial ascites method: percutaneous treatments for hepatocellular carcinoma located just beneath the diaphragm. Am J Gastroenterol 95: 2404-2405, 2000.

17. Montorsi M, Santambrogio R, Bianchi P, et al: Radiofrequency interstitial thermal ablation of hepatocellular carcinoma in liver cirrhosis. Role of the laparoscopic approach. Surg Endosc 15: 141-145, 2001.

18. Patterson EJ, Scudamore CH, Owen DA, Nagy AG and Buczkowski AK: Radiofrequency ablation of porcine liver in vivo: effects of blood flow and treatment time on lesion size. Ann Surg 227: 559-565, 1998.

19. Yamasaki T, Kurokawa F, Shirahashi H, Kusano N, Hironaka K and Okita K: Percutaneous radiofrequency ablation therapy for patients with hepatocellular carcinoma during occlusion of hepatic blood flow. Comparison with standard percutaneous radiofrequency ablation therapy. Cancer 95: 2353-2360, 2002.

20. Yang SD, Lee SC and Chang HC: Heat stress induces tyrosine phosphorylation/activation of kinase FA/GSK-3 alpha (a human carcinoma dedifferentiation modulator) in A431 cells. J Cell Biochem 66: 16-26, 1997.

21. Llovet JM, Vilana R, Bru C, et al: Increased risk of tumor seeding after percutaneous radiofrequency ablation for single hapatocellular carcinoma. Hepatology 33: 1124-1129, 2001.

22. Siperstein A, Garland A, Engle K, et al: Local recurrence after laparoscopic radiofrequency thermal ablation of hepatic tumors. Ann Surg Oncol 7: 106-113, 2000.

23. Wood TF, Rose DM, Chung M, Allegra DP, Foshag LJ and Bilchik AJ: Radiofrequency ablation of 231 unresectable hepatic tumors: indications, limitations and complications. Ann Surg Oncol 7: 593-600, 2000. 